\title{
Biodegradable nanoparticles combining cancer cell targeting and anti-angiogenic activity for synergistic chemotherapy in epithelial cancer
}

\author{
Francesca Moret ${ }^{1}$. Claudia Conte ${ }^{2} \cdot$ Diletta Esposito $^{2} \cdot$ Giovanni Dal Poggetto $^{3} \cdot$ Concetta Avitabile $^{4}$. \\ Francesca Ungaro ${ }^{2}$. Natascia Tiso ${ }^{1} \cdot$ Alessandra Romanelli $^{5} \cdot$ Paola Laurienzo $^{3} \cdot$ Elena Reddi $^{1} \cdot$ Fabiana Quaglia $^{2,3}$ (I)
}

Accepted: 25 October 2021 / Published online: 1 January 2022

(c) The Author(s) 2021

\begin{abstract}
A biodegradable engineered nanoplatform combining anti-angiogenic activity and targeting of cancer cells to improve the anticancer activity of docetaxel (DTX) is here proposed. Indeed, we have developed biodegradable nanoparticles (NPs) of poly(ethylene glycol)-poly( $\varepsilon$-caprolactone), exposing on the surface both folate motifs (Fol) for recognition in cells overexpressing Folate receptor- $\alpha(\mathrm{FR} \alpha)$ and the anti-angiogenic hexapeptide aFLT1. NPs showed a size around $100 \mathrm{~nm}$, the exposure of $60 \%$ of Fol moieties on the surface, and the ability to entrap DTX and sustain its release with time. NPs were stable in simulated biological fluids and slightly interacted with Fetal Bovine serum, especially in the formulation decorated with Fol and aFLT1. The presence of Fol on NPs did not impair the anti-angiogenic activity of aFLT1, as assessed by in vitro tube formation assay in HUVEC endothelial cells. In both 2D and 3D KB cell cultures in vitro, the cytotoxicity of DTX loaded in NPs was not significantly affected by Fol/aFLT1 double decoration compared to free DTX. Remarkably, NPs distributed differently in 3D multicellular spheroids of FR $\alpha$-positive KB cancer cells depending on the type of ligand displayed on the surface. In particular, NPs unmodified on the surface were randomly distributed in the spheroid, whereas the presence of Fol promoted the accumulation in the outer rims of the spheroid. Finally, NPs with Fol and aFLT1 gave a uniform distribution throughout the spheroid structure. When tested in zebrafish embryos xenografted with KB cells, NPs displaying Fol/ aFLT1 reduced DTX systemic toxicity and inhibited the growth of the tumor mass and associated vasculature synergistically. Overall, nanotechnology offers excellent ground for combining therapeutic concepts in cancer, paving the way to novel multifunctional nanopharmaceuticals decorated with bioactive elements that can significantly improve therapeutic outcomes.
\end{abstract}

Keywords Polymeric nanoparticles $\cdot$ Anti-angiogenic peptides $\cdot$ Folate targeting $\cdot$ Tumor spheroids $\cdot$ Xenografted zebrafish embryos

\section{Introduction}

In the vast arena of nanoplatforms developed so far for the delivery of chemotherapeutics, multifunctional polymeric nanoparticles (NPs) bearing different elements in a single

Francesca Moret and Claudia Conte equally contributed to this work.

Elena Reddi

elena.reddi@unipd.it

$\triangle$ Fabiana Quaglia

quaglia@unina.it

1 Department of Biology, University of Padova, Padova 35121, Italy

2 Department of Pharmacy, University of Napoli Federico II, Napoli 80131, Italy entity offer an unprecedented tool of innovation [1-4]. This type of NPs can be engineered: (i) to transport the chemotherapeutic in the desired pathological area; (ii) to target specific cell population in the tumor microenvironment; (iii) to deliver multiple drugs and attain synergic/additive effects.

Amphiphilic diblock copolymers of poly(ethylene glycol) and polyesters are biocompatible and biodegradable versatile materials that form a wide range of core-shell nanostructures

3 Institute for Polymers, Composites and Biomaterials, CNR, Pozzuoli 80078, Italy

4 Institute of Biostructure and Bioimaging, CNR, Napoli 80134, Italy

5 Department of Pharmaceutical Sciences, University of Milan, Milano 20133, Italy 
and deliver multiple drugs in a sustained manner [5-7]. The presence of an outer PEG fringe makes the surface hydrophilic, which is helpful in limiting some undesired interactions with the biophase (opsonization in the blood compartment) [8] and facilitating transport through mucosal tissues or extracellular matrix [9-11]. PEGylation is a two swords strategy since the benefits mentioned above are coupled with a poor attitude of NPs to cross the cell membrane and deliver drug cargo inside cells [12]. For these reasons, surface-modification of NPs with ligands binding cell membrane receptors has been attempted to improve their selective internalization in specific cell types of tumor microsystem [3,13].

Folate receptor- $\alpha(F R \alpha)$ is one of the most studied surface receptors employed for this purpose since it is overexpressed in several cancer types [14]. However, the control over Folate (Fol) exposure on NPs surface is not trivial at all when assembling NPs from all in one block copolymers [15] and poorly investigated $[13,16]$. We have recently proposed different strategies for the effective display of Fol motifs on the surface of PEGylated NPs through appropriate tailoring of polymer block lengths and fabrication conditions [16-18]. Results have demonstrated a certain degree of specificity of the NPs for cancer cells overexpressing FR $\alpha$, although no gain in cytotoxicity was observed.

Besides being a somewhat common targeting strategy, surface modification of NPs with functional motifs represents a unique tool to impart synergistic effects [2]. In the context of cancer, angiogenesis is an orchestrated process crucial for the growth, invasion, and metastasis of a primary tumor [19]. The concept that dysfunctional vasculature is common to a wide range of solid cancers has pushed the interest in tumor vascular targeting [20, 21]. Furthermore, stromal cells, unlike neoplastic cells, are genetically more stable, being less prone to develop resistance to therapy [22]. VEGF is the most relevant player in tumor angiogenesis since its inhibition influences endothelial cell survival/ growth/migration, blood flow, and stromal cell recruitment [23]. Anti-angiogenic therapy in cancer has reached maturity, and distinct types of angiogenic inhibitors, such as antibodies and small molecules, have been introduced in the clinic (bevacizumab, tyrosine kinase inhibitors) to potentiate the response to chemotherapy, patient outcome, and survival in different cancer types [24]. However, nonselective anti-angiogenic therapies require repeated i.v. administration [25] and may lead to a worse response in terms of drug resistance, invasion, and metastasis [26]. To address the urgent need for new nano-oriented approaches in anti-angiogenic therapies [27], we have recently built up NPs of PEG-poly( $\varepsilon$-caprolactone) (PEG-PCL) surfacemodified with the anti-angiogenic anti-FLT1 hexapeptide (aFLT1, GNQWFI), which selectively binds VEGFR1 isoform expressed in tumor dysfunctional capillaries [28, 29].
We found that NPs decorated with aFLT1 were superior to free aFLT1 in inhibiting tube vessel formation in vitro and potentiated the anticancer activity of docetaxel (DTX) in chicken embryo chorioallantoic membranes (CAM) xenografted with human triple-negative breast cancer cells [30].

Based on these premises, here we propose an improved multifunctional therapeutic NP for the delivery of DTX, which combines aFLT1 anti-angiogenic activity with Fol targeting. NPs, carrying the therapeutic cargo DTX in the core, are prepared from PEG-PCL copolymers conjugated with Fol and aFLT1 at the PEG-OH end group. After an indepth characterization of NPs, their biological profile was tested in 2D and 3D cultures of FR $\alpha$ over-expressing KB human cervical cancer cells and zebrafish embryos xenografted with the same type of cells.

\section{Materials and methods}

\section{Materials}

mPEG-PCL (mPEG of 1.0 kDa, mPEG-PCL Mn $5.4 \mathrm{kDa}$ ), Fol-PEG-PCL (mPEG of $1.0 \mathrm{kDa}$, PCL Mn $4.7 \mathrm{kDa}$ ), and aFLT1-PEG-PCL (mPEG of $1.0 \mathrm{kDa}$, PCL Mn $4.7 \mathrm{kDa}$ ) were synthesized and characterized according to the procedures reported in our previous studies [17]. Docetaxel (DTX) was purchased from LC laboratories (USA). 3,3'-dioctadecyloxacarbocyanine perchlorate (DiO) was purchased from ThermoFisher Scientific (Italy). Sodium chloride, potassium phosphate dibasic and potassium phosphate monobasic, sodium azide, and potassium chloride were used as received from Sigma Aldrich. All other solvents and chemicals were purchased from Sigma Aldrich (Milan, Italy) and used as received.

\section{Preparation of NPs}

We prepared bare PEGylated NPs (DBL) from mPEG-PCL copolymer, folate-targeted NPs $\left(\mathrm{DBL}_{\mathrm{Fol}}\right)$ from mPEGPCL/Fol-PEG-PCL (8:2 by weight, respectively), and anti-angiogenic folate-targeted NPs $\left(\mathrm{DBL}_{\mathrm{Fol} / \mathrm{aFLT} 1}\right)$ from mPEG-PCL/Fol-PEG-PCL/aFLT1-PEG-PCL ( 7:2:1 by weight, respectively). NPs were obtained by solvent diffusion of an organic phase (10 mg of copolymer/s in $1 \mathrm{~mL}$ of acetone) added dropwise in water $(2 \mathrm{~mL})$ under magnetic stirring $(500 \mathrm{rpm})$. The addition of a surfactant was not required. After solvent evaporation, NPs were filtered through $0.45 \mu \mathrm{m}$ Phenex ${ }^{\circledR}$ filters (Phenomenex, USA). NPs loaded with DTX were prepared according to the procedure reported above by adding DTX $(1 \mathrm{mg})$ in acetone. Fluorescent NPs loaded with DiO were prepared with the same method by adding $\mathrm{DiO}(0.1 \mathrm{mg})$ in the organic phase. 


\section{NP characterization}

The hydrodynamic diameter $\left(\mathrm{D}_{\mathrm{H}}\right)$, polydispersity index $(\mathrm{PI})$, and zeta potential $(\xi)$ of NPs were determined on a Zetasizer Nano ZS (Malvern Instruments Ltd). Results are reported as the mean of three separate measurements of three different batches $\pm \operatorname{SD}(n=9)$. The yield of the NPs production process was evaluated on an aliquot of NPs dispersion by weighting the solid residue after freezedrying. Results are expressed as the ratio of the actual NPs weight to the theoretical polymer or polymer + drug weight $\times 100 \pm \operatorname{SD}(n=3)$.

DTX loading inside NPs was assessed by placing NPs $(1 \mathrm{mg})$ in $500 \mu \mathrm{L}$ of acetonitrile under stirring and then adding $500 \mu \mathrm{L}$ of water. After that, the sample was filtered through a $0.45 \mu \mathrm{m}$ filter (RC, Chemtek, Italy) and analyzed to evaluate the DTX amount according to a previously reported HPLC method [31]. Briefly, the analysis was carried out on a Shimadzu apparatus (Japan) on a Juppiter $5 \mu \mathrm{m}, \mathrm{C} 18$ column. The mobile phase was a 55:45 (v/v) mixture of $0.1 \%$ TFA in water and acetonitrile pumped at a flow rate of $1 \mathrm{~mL} \mathrm{~min}{ }^{-1}$. The UV detector was set at $227 \mathrm{~nm}$. A calibration curve for DTX in ethanol was plotted in the concentration range of $2-200 \mu \mathrm{g} \mathrm{mL}^{-1}$. The release of DTX was determined on NPs $(0.5 \mathrm{mg})$ dispersed in $0.5 \mathrm{~mL}$ of $10 \mathrm{mM}$ phosphate buffer containing $\mathrm{NaCl}$ $(137 \mathrm{mM})$ and $\mathrm{KCl}(2.7 \mathrm{mM})$ at $\mathrm{pH} 7.4(\mathrm{PBS})$ at $37{ }^{\circ} \mathrm{C}$ and placed in a dialysis bag. The external phase $(5 \mathrm{~mL})$ was PBS again. At predetermined times, $1 \mathrm{~mL}$ aliquots of the sample were collected and then analyzed by HPLC.

Fixed aqueous layer thickness (FALT) of NPs was measured by monitoring the influence of ionic strength on $\xi$. Different amounts of $\mathrm{NaCl}$ stock solutions were added to NPs dispersed in water $(250 \mu \mathrm{g} / \mathrm{mL})$ and the zeta potential of the samples was measured. A plot of $\ln \xi$ against $3.33^{*}[\mathrm{NaCl}]^{0.5}$ gives a straight line where the slope represents the thickness of the shell in $\mathrm{nm}$ [32].

To evaluate the stability of NPs under physiologically relevant conditions, a known amount of NPs $(1 \mathrm{mg})$ was diluted in PBS at $\mathrm{pH} 7.4$ (NPs concentration $1 \mathrm{mg} / \mathrm{mL}$ ) and incubated at $37{ }^{\circ} \mathrm{C}$ for different times. Size measurements of the samples were taken after $15 \mathrm{~min}, 1,2$, and $24 \mathrm{~h}$ of incubation as described above.

\section{Dosage of folate exposure}

Detection of folate on the NP surface was accomplished by incubating NPs with a specific mAB-antiFol (monoclonal anti-folic acid antibody produced in mouse, Sigma Aldrich) and determining its amount using the Bradford Assay. Briefly, $0.1 \mathrm{~mL}$ of NPs $(5 \mathrm{mg} / \mathrm{mL})$ were mixed with $0.1 \mathrm{~mL}$ of mAB-antiFol solution $(34 \mu \mathrm{g} / \mathrm{mL})$ in $10 \mathrm{mM}$ PBS at $\mathrm{pH}$ 7.4, and the resulting solutions incubated for $1 \mathrm{~h}$ under mild shaking. The samples were then washed twice with PBS to remove the excess antibody after centrifugation at $270,000 \times g$ for $20 \mathrm{~min}$ and finally re-dispersed in $0.5 \mathrm{~mL}$ of PBS followed by the addition of $500 \mu \mathrm{L}$ of Bradford reagent. The resultant solutions were heated at $60{ }^{\circ} \mathrm{C}$ for $30 \mathrm{~min}$ and analyzed by UV spectrophotometry at $595 \mathrm{~nm}$ (Shimadzu UV 1800) according to the manufacturer's instructions. Using a calibration curve of free $\mathrm{mAB}$-antiFol in PBS, the percentage of $\mathrm{mAB}$ bound to NP surface was determined. Each assay was repeated 3 times (each with $n=3$ samples) and the average value was taken as the representative.

\section{Interaction of NPs with fetal bovine serum}

Interaction of NPs with FBS was assessed by fluorescence spectroscopy to determine the "quenching" effect of NPs on the ability of specific residues of the protein to emit light. For the experiment, $200 \mu \mathrm{L}$ of NPs ( $1 \mathrm{mg}$ ) were mixed with $800 \mu \mathrm{L}$ of RPMI cell culture medium enriched with $10 \%$ FBS, and incubated at RT for $1 \mathrm{~h}$. Then, the emission spectra were acquired $(\mathrm{Ex}=278 \mathrm{~nm})(\mathrm{RF}-6000$, Shimadzu Corporation, Japan).

\section{Generation of spheroids and NP penetration}

Multicellular spheroids of KB cells (ATCC, USA) were generated using the liquid overlay method, as previously reported [33]. After 3 days of growth, the spheroids had reached a diameter of about $500 \mu \mathrm{m}$ and were used for the following experiments.

Three-day-old KB spheroids were treated for $48 \mathrm{~h}$ with $50 \mu \mathrm{g} / \mathrm{mL}$ of DiO-loaded NPs. The localization/penetration of NPs was evaluated by confocal microscopy (Leica SP5) by transferring the spheroids from 96-well plates to $35 \mathrm{~mm}$ cell imaging dishes and washing them twice with PBS before visualization. Images of about 20 different focal planes $(z$-stack $10 \mu \mathrm{m})$ were acquired from the top to the bottom of the spheroid using a 10X objective. DiO fluorescence was revealed using a $488 \mathrm{~nm}$ laser as the excitation source and emission filters set from 505 to $550 \mathrm{~nm}$. Maximum projection images were obtained with the software LAS AF Lite by superimposing the images of the 20 acquired focal planes. Furthermore, a 3D reconstruction of the distribution of the fluorescence signal in the equatorial plane of spheroids was obtained using the software ImageJ.

\section{Cytotoxicity in spheroids}

For cytotoxicity, spheroids were incubated for 48 or $72 \mathrm{~h}$ with $100 \mu \mathrm{L}$ of fresh medium containing 10\% FBS and increasing concentration of free DTX or DTX-loaded NPs. Cell viability was measured at the end of incubation times using the CellTiter-Glo® ${ }^{\circledR}$ D Cell Viability Assay 
(Promega), as previously reported [34]. During the experiment, the spheroid morphological changes were monitored with a bright-field microscope (DMI6000B, Leica) equipped with a DCF365FX camera.

\section{Zebrafish handling and xenotransplantation}

Experiments were performed at the Zebrafish Facility of the University of Padova, under ethical authorization 407/2015PR. Embryos were obtained from natural spawning of Casper mutants (a9-w2 double mutant line; ZFIN IDs: ZDBALT-980203-444, ZDB-ALT-990423-22) and fila:EGFP transgenic adults (ZFIN ID: ZDB-ALT-011017-8), raised according to standard protocols [35] and staged according to Kimmel et al. [36] For xenotransplantation, embryos were mechanically dechorionated at 2 days post-fertilization (dpf), anesthetized with $0.16 \mathrm{mg} / \mathrm{mL}$ tricaine, and placed along the lanes of a microinjection mold, immersed in $2 \%$ methylcellulose/fish-water. $\mathrm{KB}$ cells were suspended at a density of $1 \times 10^{6} / \mathrm{mL}$ and stained with $5 \mu \mathrm{g} / \mathrm{mL}$ of DiI Vybrant Cell-Labeling Solution (Molecular Probes) for $20 \mathrm{~min}$ at $37^{\circ} \mathrm{C}$. Stained cells were loaded into a glass capillary needle and microinjected into the yolk (about 100 cells/embryo), using a WPI PicoPump apparatus. Twenty-four hours after tumor transplantation ( $3 \mathrm{dpf}$ ), embryos were microinjected using the same procedures described above with an aqueous solution of phenol red (control), free DTX, DTX-loaded NPs (DTX-DBL, DBL $\mathrm{Fol}_{\mathrm{Fol}}, \mathrm{DBL}_{\mathrm{Fol} / \mathrm{aFLT1}}$ ), and unloaded $\mathrm{DBL}_{\mathrm{Fol} / \mathrm{FLTT} 1}$. Each embryo was injected with a DTX dose of about $2.5 \mathrm{ng}$; each experimental group of treatment was constituted of 25 embryos. Xenotransplanted embryos were grown at $33{ }^{\circ} \mathrm{C}$ and monitored daily starting from the injection day up to 1 week post-injection (experimental endpoint, $9 \mathrm{dpf}$ ). Non-xenografted embryos injected with DTX formulations were observed in parallel. Analyses included mortality rate, in situ (yolk) or metastatic (extra yolk) cancer cell location, and tumor size reduction evaluation, performed by cell counting/signal quantification using ImageJ software. Imaging was performed using a Leica MZFLIII fluorescence-dissecting microscope equipped with a Leica DFC7000T camera.

For the analysis of neo-angiogenesis, the fila:EGFP transgenic line, having blood vessels and micro-vessels visible in green fluorescence, was used. The embryos ( $2 \mathrm{dpf})$ were injected with KB cells and $1 \mathrm{~h}$ later with DTX or DTX$\mathrm{DBL}_{\mathrm{Fol} / \mathrm{aFLT1}}$. Tumor and blood vessels were analyzed $48 \mathrm{~h}$ later by fluorescence microscopy.

\section{Statistical analysis}

The Primer software for biostatistics (McGraw-Hill, Columbus, USA) was used for statistical analysis of the data. The data are expressed as means \pm standard deviations (SD) for at least 3 independent experiments. The difference between groups was evaluated with the Student's $t$-test and was considered significant for $p<0.05$.

\section{Results and discussion}

\section{NP preparation and characterization}

In this work, we conceived a multifunctional NP for cancer therapy applications, in which the active targeting of the therapeutic cargo is complemented with anti-angiogenic effects. Accordingly, we designed a NP delivering DTX based on a mix of PCL-PEG copolymers, some modified at the PEG end chain with either aFLT1 or Fol to obtain the multifunctional nanoplatform with double decoration $\left(\mathrm{DBL}_{\mathrm{Fol} / \mathrm{FLT1}}\right)$ (Fig. 1A). For comparison purposes, unmodified NPs of PEG-PCL (DBL) or Fol-PEG-PCL/PEG-PCL $\left(\mathrm{DBL}_{\mathrm{Fol}}\right)$ were prepared. Unloaded or DTX-loaded NPs were obtained by the solvent diffusion/evaporation method. The ratio between Fol-PEG-PCL/PEG-PCL and Fol-PEG-PCL/ aFLT1-PEG-PCL was selected based on our previous findings $[17,30]$. It is worth noting that the manipulation space of the formulation was limited by aggregation in the nanoprecipitation step when Fol-PEG-PCL or aFLT1-PEG-PCL amount was increased and that of PEG-PCL was decreased. The overall properties of the NPs are reported in Table 1.

All the formulations show a $D_{\mathrm{H}}$ between 78 and $101 \mathrm{~nm}$, a low polydispersity index, and a negative $\zeta$. NPs prepared from copolymer mix $\left(\mathrm{DBL}_{\mathrm{Fol}}\right.$ and $\left.\mathrm{DBL}_{\mathrm{Fol} / \mathrm{aFLT1}}\right)$ are larger than DBL, suggesting that segregation of hydrophilic blocks in the PCL core occurs [17].

In Fig. 1B, the values of $\xi$ in $\mathrm{NaCl}$ solutions at different concentrations are shown. The thickness of the external hydrophilic PEG shell of NPs, which is the slope of the regression lines in absolute value, is similar for the NPs tested, thus suggesting that the presence of surface motifs has a slight impact on the conformation of the PEG present on the surface of NPs (Fig. 1B). DTX entrapment in the lipophilic core of NPs (9\% theoretical loading) is almost complete and does not affect the colloidal properties of NPs.

The release of DTX from NPs (Fig. 1C), evaluated in $10 \mathrm{mM}$ PBS at pH 7.4 and $37{ }^{\circ} \mathrm{C}$ by dialysis, is bimodal for all the formulations. The burst in the $0-6 \mathrm{~h}$ interval is higher for NPs obtained from copolymer mix than bare DBL, in line with the hypothesis that some hydrophilic blocks in the PCL core matrix decrease the crystallinity of NPs and increase the diffusivity of the entrapped DTX. Release of DTX is completed in ca. $72 \mathrm{~h}$ for all the formulations tested. Free DTX is quantitatively released in the external medium in ca. $6 \mathrm{~h}$, ensuring sink conditions.

As shown in Fig. 2A, NPs show excellent stability in PBS pH 7.4 at $37{ }^{\circ} \mathrm{C}$, employed as simulated biological studies 


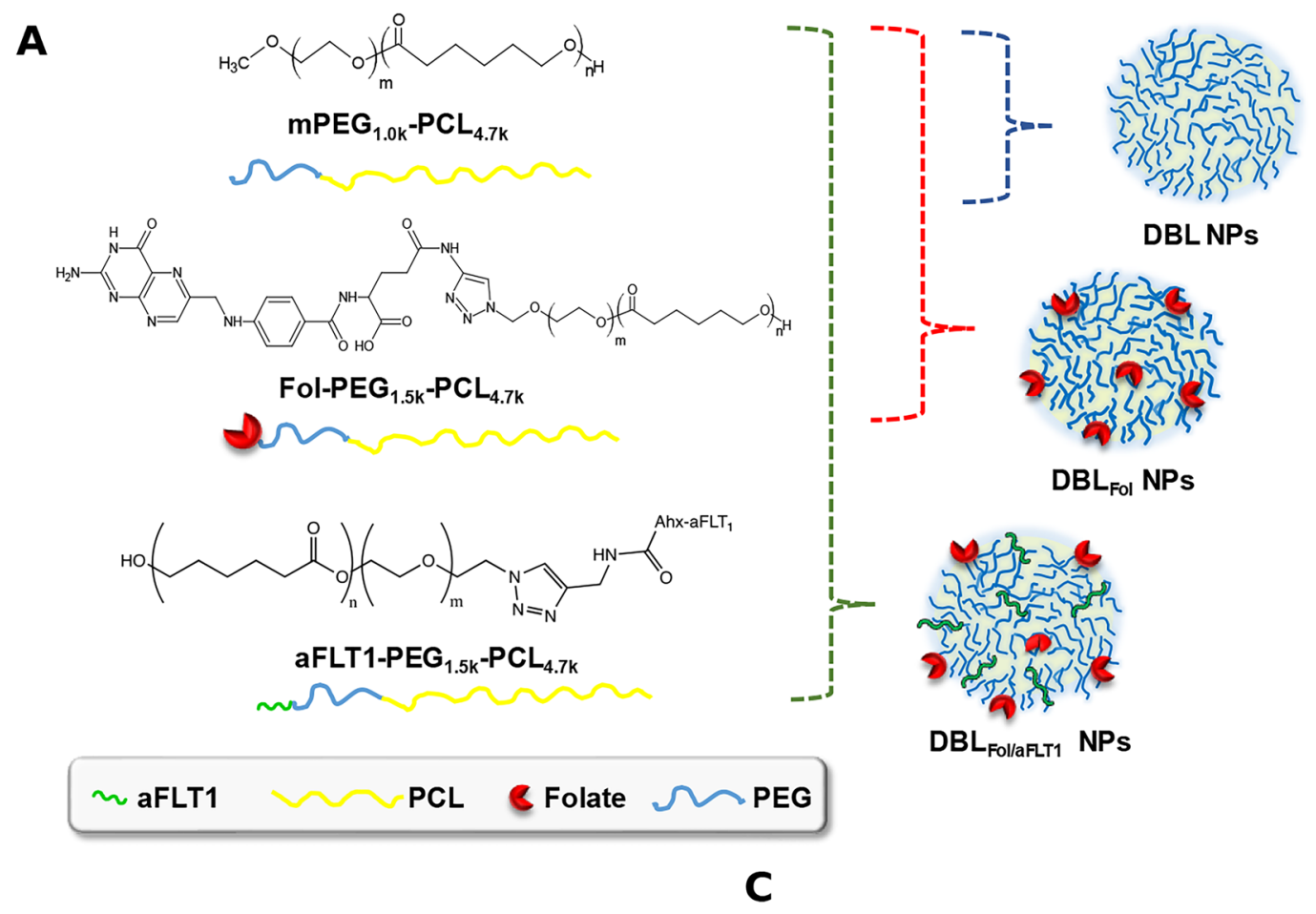

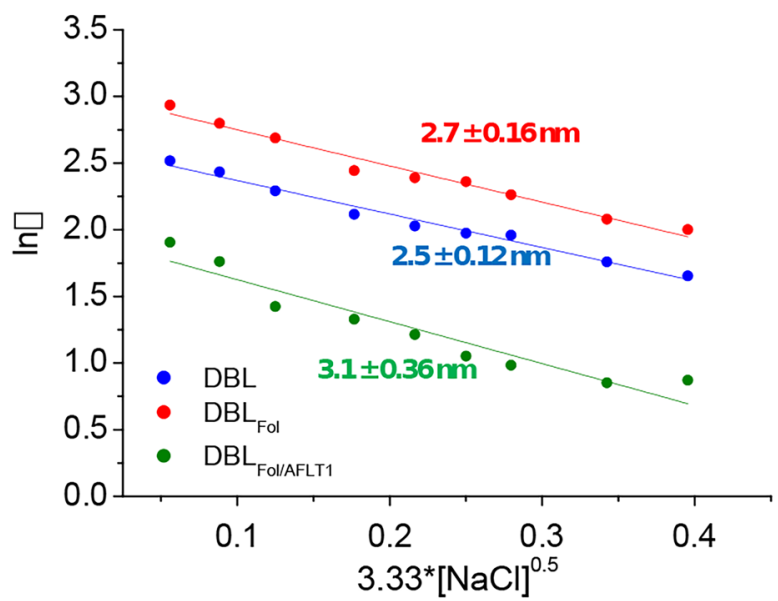

Fig. 1 A Chemical structure of the copolymers employed to prepare NPs. B Representative Fixed aqueous layer thickness (FALT) measurements evaluated by monitoring the zeta potential of NPs dispersed in $\mathrm{NaCl}$ solutions in water $([\mathrm{NPs}]=250 \mu \mathrm{g} / \mathrm{mL})$ : the slope of the straight line represents the thickness of the outer hydrophilic

until $24 \mathrm{~h}$ of incubation. Then, the folate exposure on the NP surface was checked through the binding with a specific mAB against folate. As evident in Fig. 2B, a 40\% antibody was able to bind $\mathrm{DBL}_{\mathrm{Fol}}$ and $\mathrm{DBL}_{\mathrm{Fol} / \mathrm{FFT} 1}$ NPs, independently by the presence of the anti-angiogenic peptide. The experiment was carried out also on untargeted NPs as a negative control.

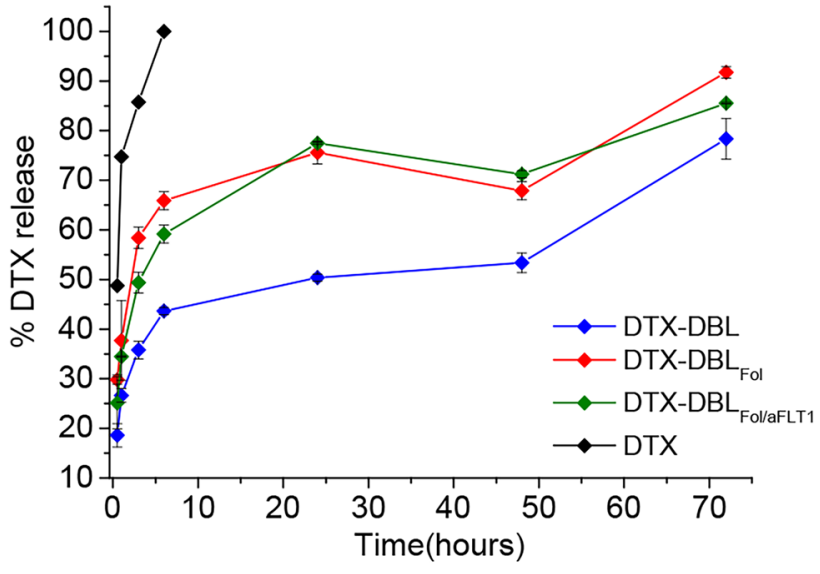

shell expressed in nm. C Docetaxel (DTX) release from NPs in PBS $10 \mathrm{mM} \mathrm{pH} \mathrm{7.4,} \mathrm{at} 37^{\circ} \mathrm{C}$ evaluated by the dialysis method. Results are the mean values $\pm \mathrm{SD}$ of three measurements carried out on three different NPs batches

Then, before moving to in vitro and in vivo experimentation, we checked NPs interaction with proteins present in simulated biological fluids. Thus, NPs were dispersed in RPMI cell culture medium added with $10 \%$ fetal bovine serum (FBS) and the quenching of FBS emission after excitation at $278 \mathrm{~nm}$ was evaluated. We found a similar interaction between the proteins and the different formulations, 
Table 1 Properties of unloaded and DTX-loaded NPs

\begin{tabular}{|c|c|c|c|c|c|c|}
\hline Formulation & $\begin{array}{l}D_{\mathrm{H}} \\
(\mathrm{nm} \pm \mathrm{SD})\end{array}$ & PI & $\zeta_{(\mathrm{mV} \pm \mathrm{SD})}$ & $\begin{array}{l}\text { Yield } \\
(\% \pm \mathrm{SD})\end{array}$ & $\begin{array}{l}\text { DTX actual } \\
\text { loading } \\
\text { (mg } \\
\text { DTX/100-mg } \\
\text { NPs) }\end{array}$ & $\begin{array}{l}\text { DTX } \\
\text { entrapment eff. }{ }^{\text {a }} \\
(\%)\end{array}$ \\
\hline DBL & $78 \pm 2$ & 0.1 & $-12 \pm 0.1$ & $68 \pm 4$ & - & - \\
\hline $\mathrm{DBL}_{\mathrm{Fol}}$ & $84 \pm 5$ & 0.1 & $-18 \pm 6$ & $52 \pm 3$ & - & - \\
\hline $\mathrm{DBL}_{\mathrm{Fol} / / \mathrm{FLT} 1}$ & $101 \pm 8$ & 0.2 & $10 \pm 3$ & $54 \pm 1$ & - & - \\
\hline DTX-DBL & $92 \pm 5$ & 0.2 & $-10 \pm 1$ & $72 \pm 6$ & $8.8 \pm 0.9$ & $98 \pm 4$ \\
\hline DTX-DBL ${ }_{\text {Fol }}$ & $84 \pm 8$ & 0.1 & $-19 \pm 4$ & $61 \pm 4$ & $8.7 \pm 1.5$ & $98 \pm 10$ \\
\hline DTX-DBL ${ }_{\mathrm{Fol} / \mathrm{FLT} 1}$ & $101 \pm 5$ & 0.1 & $-9 \pm 2$ & $55 \pm 3$ & $8.5 \pm 0.6$ & $96 \pm 6$ \\
\hline
\end{tabular}

${ }^{\mathrm{a}}$ Theoretical loading of DTX was $9 \mathrm{mg}$ DTX per $100 \mathrm{mg}$ of NPs slightly pronounced in the case of $\mathrm{DBL}_{\mathrm{Fol} / \mathrm{FLT} 1} \mathrm{NPs}$ and $\mathrm{DBL}_{\mathrm{Fol}}$ (Fig. 2C). Finally, we confirmed the elevated antiangiogenic activity of aFLT1 displayed on the surface of $\mathrm{DBL}_{\mathrm{Fol} / \mathrm{aFLT1}}$ : compared with DBL and $\mathrm{DBL}_{\mathrm{Fol}}$, which, as expected, did not show any capacity to inhibit endothelial tube formation (Fig. S1), DBL Fol/aFLT1 $_{\text {significantly affect }}$ all tube parameters (e.g. the number of junctions, master segments and meshes).

\section{In vitro behavior of NPs in KB spheroids}

The behavior of NPs was assessed in FR $\alpha$ positive KB cells cultured as avascular spheroids to mimic more closely the in vivo three-dimensional tumor architecture and the enrichment in extracellular matrix components, which may affect drug distribution and efficacy [37]. The penetration of $\mathrm{DBL}_{\mathrm{Fol}}$ and $\mathrm{DBL}_{\mathrm{Fol} / \mathrm{aFLT} 1}$ NPs loaded with
Fig. 2 A Hydrodynamic diameter of NPs after incubation in PBS pH 7.4 at $37^{\circ} \mathrm{C}$ at different time points $([\mathrm{NPs}]=1 \mathrm{mg} / \mathrm{mL})$. B Percentage of folate exposure on NP surface measured by incubating NPs $(5 \mathrm{mg} / \mathrm{mL})$ with a monoclonal anti-folic acid antibody. Results are the mean values \pm SD of three measurements carried out on three different NPs batches. C Fluorescence emission spectra of RPMI with $10 \%$ of FBS at $\mathrm{Ex}=278 \mathrm{~nm}$ in the presence of DBL NPs, DBL Fol $_{\text {NPs }}$ and $\mathrm{DBL}_{\mathrm{Fol} / \mathrm{aFLT}}([\mathrm{NPs}]=1 \mathrm{mg} /$ $\mathrm{mL})$. The reduction of the emission of RPMI + FBS indicates an interaction between NPs and the protein
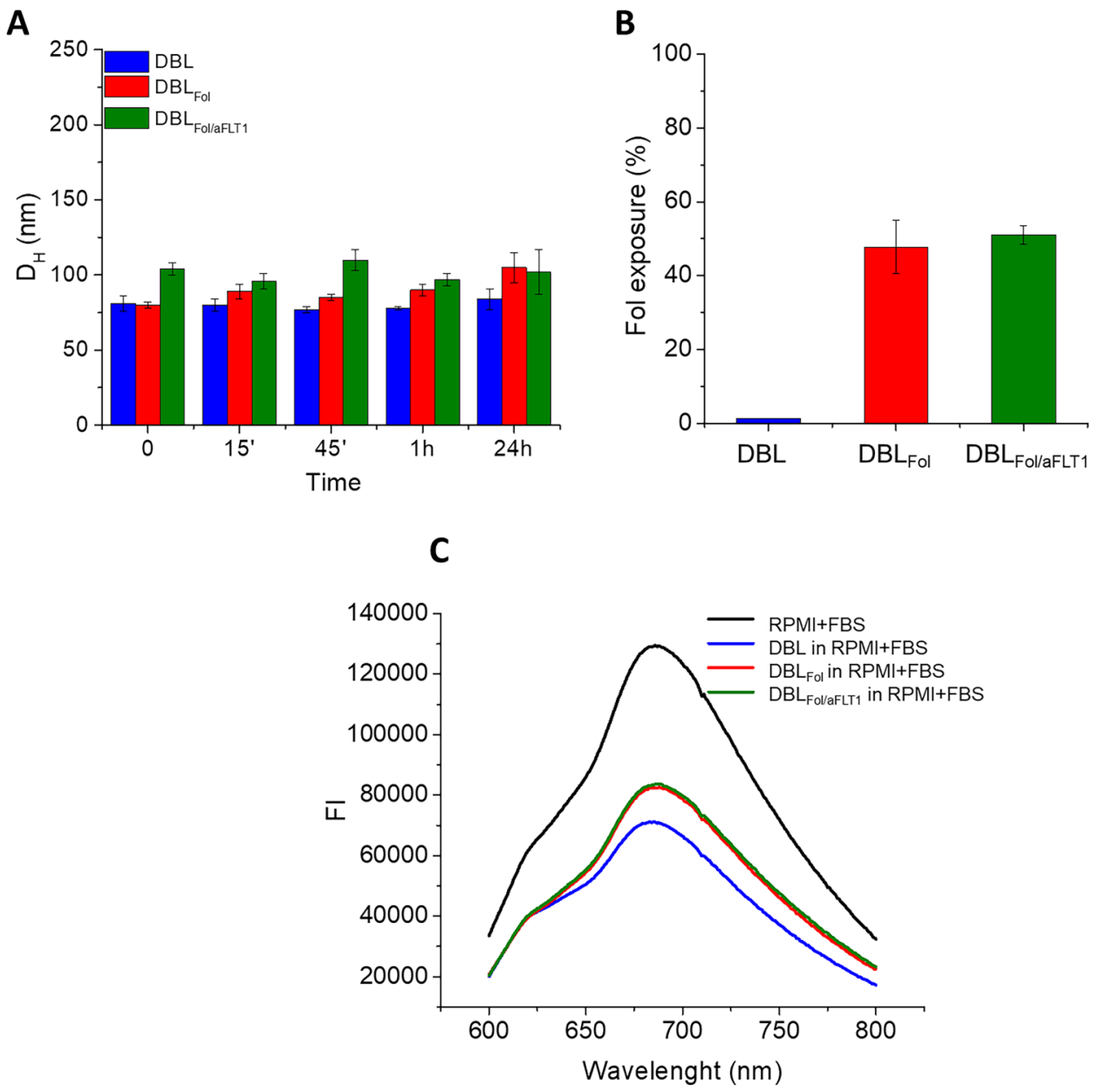
$\mathrm{DiO}$ (properties in Table $\mathrm{S} 1$ ) in $\mathrm{KB}$ spheroids is shown in Fig. 3. Confocal images, taken at the median plane of the spheroids after $48 \mathrm{~h}$ of incubation, evidence a different distribution pattern depending on NP decoration. Due to the high lipophilicity of $\mathrm{DiO}$, we assume that the green fluorescence visible in the cell aggregates can be identified with NPs. While fluorescence is randomly distributed for DBL, the green signal is confined in the outer rims for $\mathrm{DBL}_{\mathrm{Fol}}$ and uniformly distributed in the entire spheroid for $\mathrm{DBL}_{\mathrm{Fol} / \mathrm{aFLT}}$. Tridimensional plots showing fluorescence signal intensity (Fig. 4, panels c) and maximum projections (Fig. 4, panels d) revealed that NPs accumulated in the order $\mathrm{DBL}<\mathrm{DBL}_{\mathrm{Fol} / \mathrm{aFLT} 1}<\mathrm{DBL}_{\mathrm{Fol}}$ as compared to the total fluorescence. The prevalent location of $\mathrm{DBL}_{\mathrm{Fol}}$ in the spheroid rim is in line with the so-called "barrier effect" observed for NPs targeting cancer cells receptors. Surprisingly, the parallel presence of aFLT1 on NP surface attenuates this effect and promotes $\mathrm{DBL}_{\mathrm{Fol} / \mathrm{aFLT} 1}$ penetration in the whole-cell aggregate, likely due to a shielding effect exerted by peptide chains.
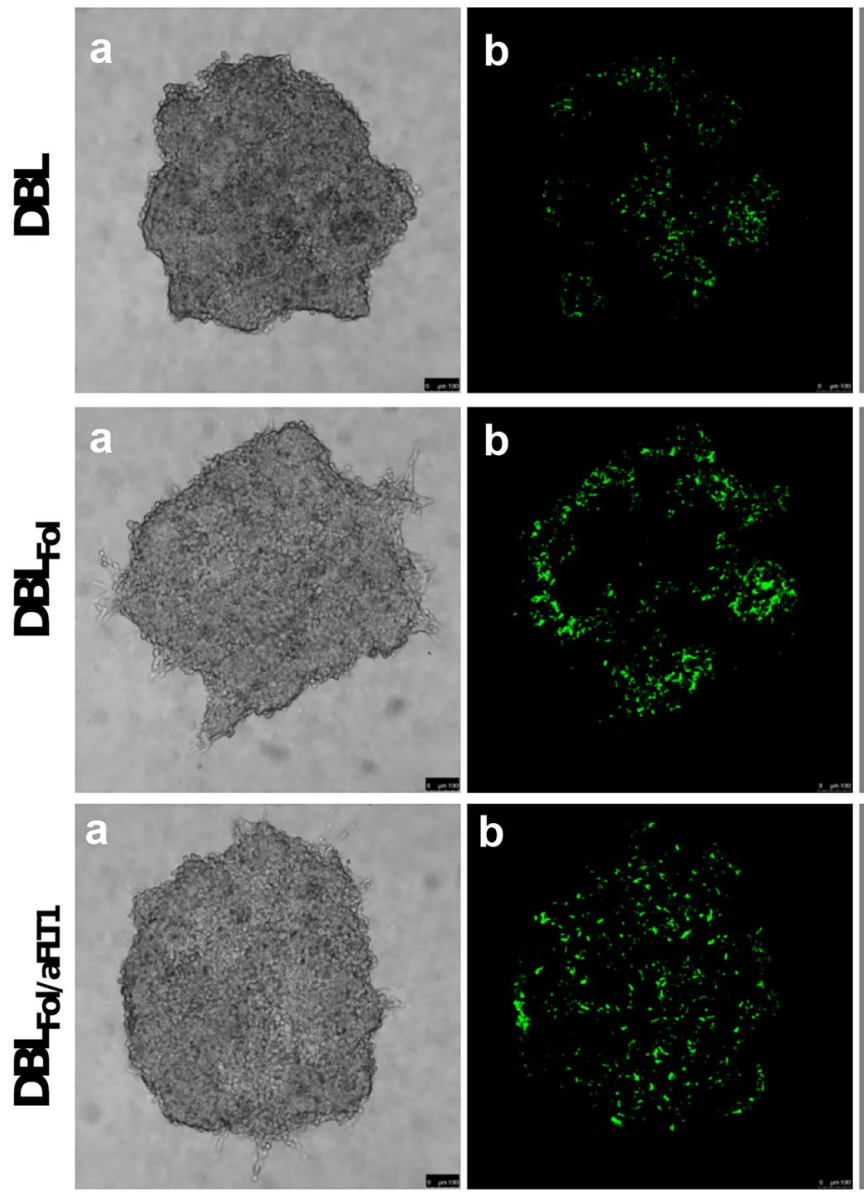

Fig. 3 Confocal images of KB spheroids after treatment with DiOloaded NPs $(50 \mu \mathrm{g} / \mathrm{mL})$ for $48 \mathrm{~h}$ : a bright-field; b DiO fluorescence acquired in the equatorial plane of the spheroid; $\mathbf{c} 3 \mathrm{D}$ reconstruction
A concentration- and time-dependent cell viability reduction was measured upon treatment of $2 \mathrm{D}$ cultures of both $\mathrm{KB}$ and HUVEC with DTX and DTX-loaded NPs (Fig. S2), after demonstration of the tolerability of unloaded NPs (Fig. S3). Cell viability of DTX-DBL ${ }_{\mathrm{Fol}}$ and DTX-DBL $\mathrm{Fol}_{\text {aFLT1 }}$ vs. DTX-DBL was not modified by surface decoration, probably due to the weak contribution of FR-mediated NPs endocytosis as compared to non-specific endocytosis, as we previously reported for monolayer cell cultures [17].

The cytotoxicity of DTX-loaded NPs measured by the 3D Glo Assay in KB spheroids after $72 \mathrm{~h}$ of treatment is reported in Fig. 4. Results are expressed as residual ATP content $v s$. untreated cells as a significant parameter to measure viability reduction and toxicity. The incubation of KB spheroids with DTX-loaded NPs determines a sharp cell viability reduction, although no significant differences between the formulations were observed independently of the time (see also Fig. S4 reporting cell viability of spheroid after $48 \mathrm{~h}$ of incubation). The cytotoxicity of free DTX is dose- and time-dependent and
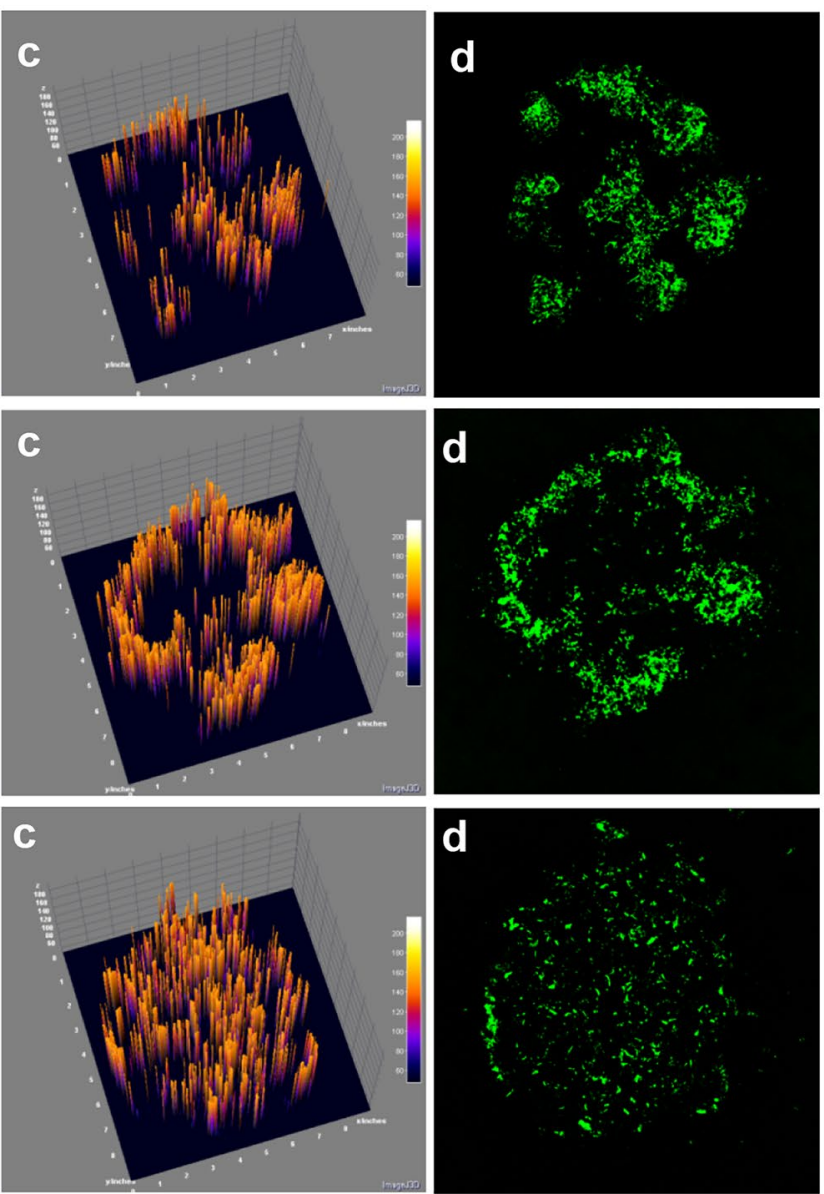

of the distribution of the fluorescence signal in the equatorial plane of the spheroid; $\mathbf{d}$ maximum projection obtained by superimposing the images of the 20 acquired focal planes. Scale bars: $100 \mu \mathrm{m}$ 
A

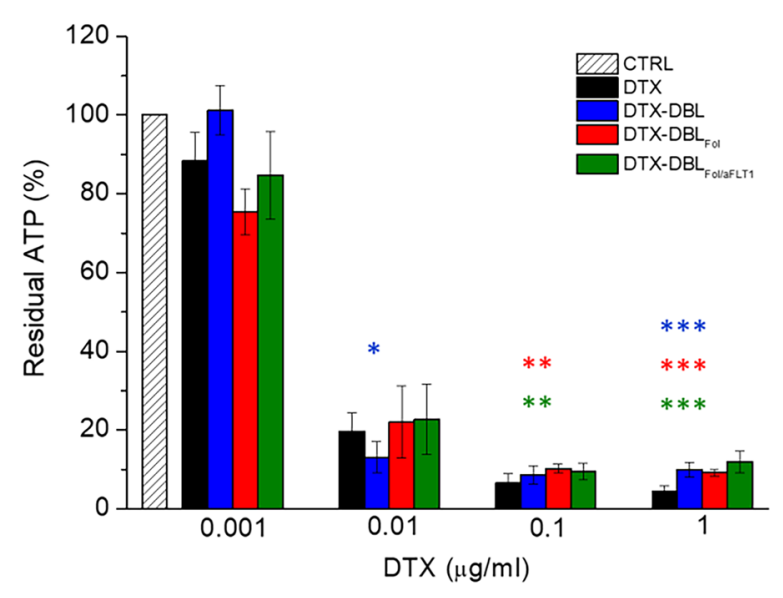

Fig. 4 Cytotoxicity of DTX-loaded NPs in KB spheroids. A Percentage of residual ATP in the spheroid measured using the CellTiterGlo® 3D Cell Viability Assay after $72 \mathrm{~h}$ of treatment with DTXloaded NPs or with the free drug $([D T X]=0.001-1 \mu \mathrm{g} / \mathrm{mL})$. Data are mean values $\pm \mathrm{SD}$ of at least three independent experiments carried

confirmed by the bright-field images of the treated spheroids (Fig. 4B and Fig. S4B), highlighting that the disaggregation of the spheroids accompanies the progressive loss of viability. As expected, the extent of cell release and mortality started from the periphery to the core of the spheroids, especially with DTX-DBL $\mathrm{Fol}_{\mathrm{f}}$ and DTX$\mathrm{DBL}_{\mathrm{Fol} / \mathrm{aFLT} 1}$ at a drug concentration of $0.01 \mu \mathrm{g} / \mathrm{mL}$ at both 48 and $72 \mathrm{~h}$. Unloaded NPs were not toxic to cell spheroids (Fig. S5).

The different pattern of cellular aggregate dissociation is consistent with the observation that Fol decoration of NPs promoted the accumulation mainly at the periphery of the spheroid and exerted cytotoxic effects prevalently in the rim. The fact that cytotoxicity of NPs is comparable with that of DTX demonstrates once again that a complex interplay between DTX release and NP transport/accumulation in the cancer cell aggregates occur, making it difficult to draw conclusions on the superior activity of NPs.

\section{In vivo anti-tumor and anti-angiogenic activity of NPs in zebrafish embryos}

As the mammalian models, zebrafish has striking evolutionary conservation of disease-related genes and pathways in humans, and thus both models are widely employed in cancer research and nanomedicine screening. The choice of using Danio rerio embryos as an exploratory in vivo nonmammalian model to study tumor regression and angiogenesis after treatment with NPs was encouraged by several preliminary considerations [38],: (i) the transparency of the

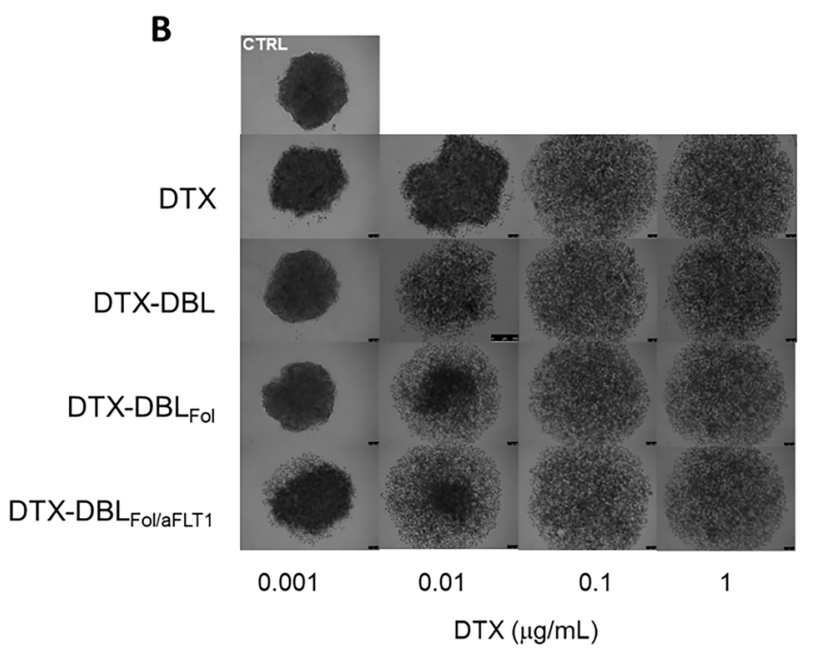

out in triplicate. ${ }^{*} p<0.05, * * p<0.01, * * * p<0.001$ vs. free DTX (Student's $t$-test). B Bright-field images of spheroids acquired by confocal microscopy after $72 \mathrm{~h}$ of treatment with DTX-loaded NPs at different doses. Scale bars: $100 \mu \mathrm{m}$

embryo, which allows easy observation of tumor development, angiogenesis, and metastasis in real-time; (ii) high physiologic and genetic similarity to mammals [38]; (iii) low cost of maintenance and ease of manipulation as compared to rodents. Furthermore, the immune system of embryos is immature up to $11 \mathrm{dpf}$, thus avoiding or delaying the rejection of xenotransplants [39]. The availability of transgenic models over-expressing fluorescent proteins (e.g., vascular proteins) also offers a tool to monitor neo-angiogenesis easily [40, 41]. Recently, zebrafish has emerged as a useful preclinical cancer model for the preliminary screening of nanomedicines [42], mainly because it allows the rapid and high-throughput in vivo evaluation of nanoformulations with more sustainable costs than rodents and satisfying at the same time the 3Rs legislative guidelines. Indeed, conventional 2D and 3D in vitro cancer models are often associated with investigations using the xenografted zebrafish model to assess NP interactions in vivo under more complex and representative biological conditions. Although no final correlation between zebrafish and mice cancer models has been drawn, the potential of zebrafish cancer avatars and how these models compare with and complement mouse xenografts and human organoids has been recently reviewed [43].

The experimental procedure in zebrafish adopted here is based on the injection of both tumor cells and NPs in the yolk of the embryo by microinjection to achieve local effects as recently demonstrated for glioblastoma [44]. The set-up of the experiments in albino zebrafish embryos xenografted with KB cells is outlined in Fig. 5A. The yolk region of 2-dpf embryos was inoculated with DiI-labeled 

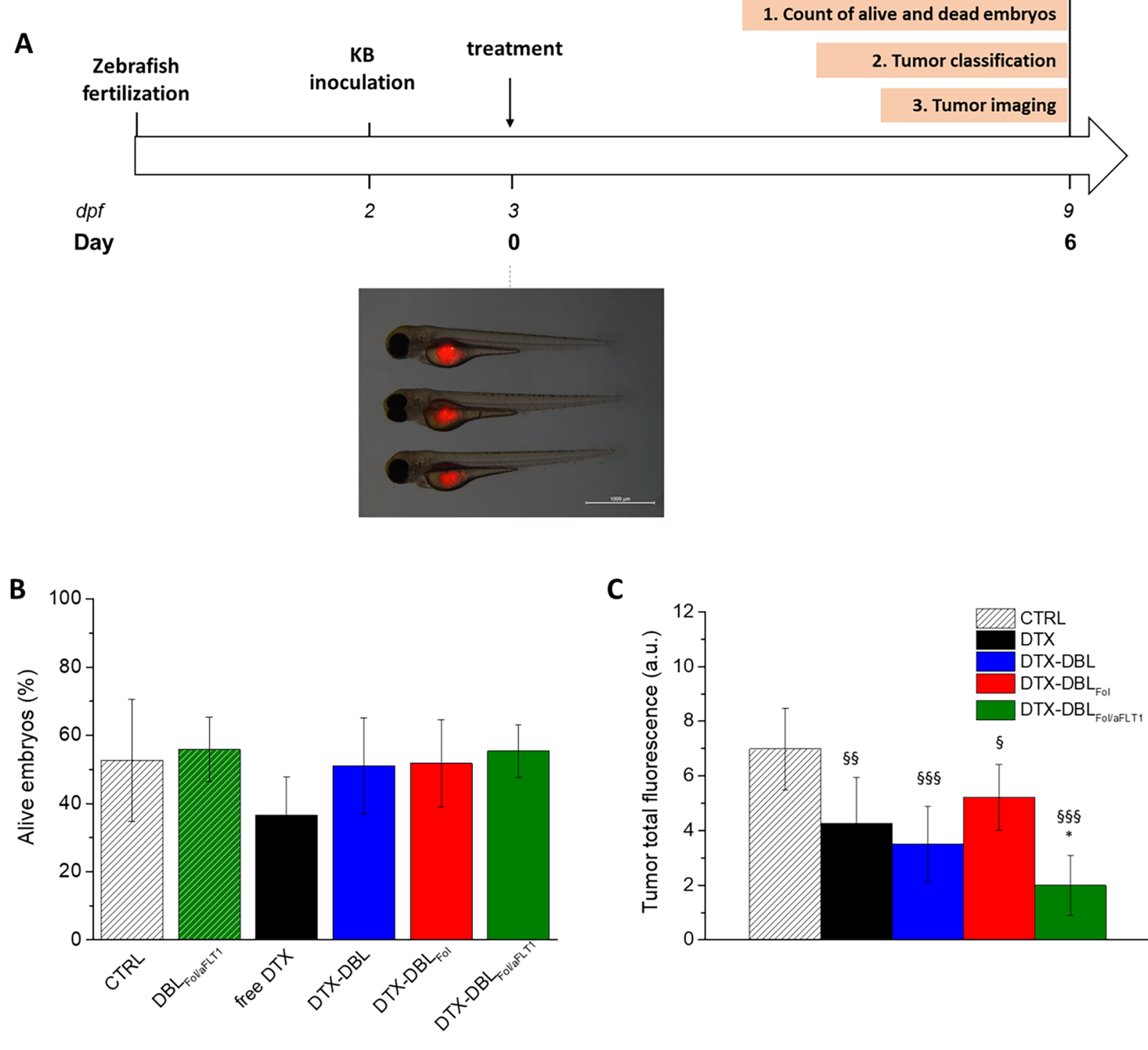

D
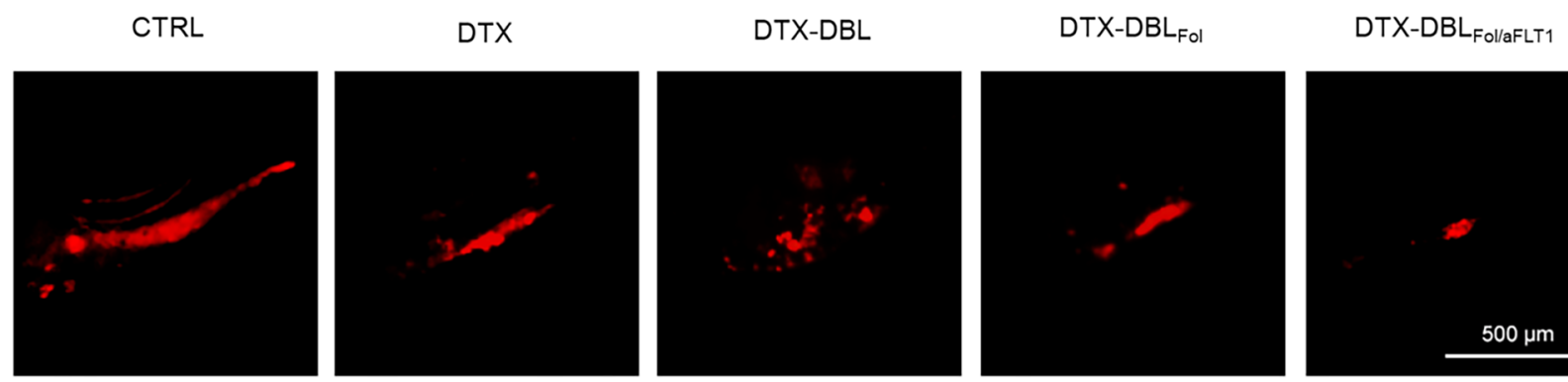

Fig. 5 Toxicity and activity of DTX-loaded NPs in the zebrafish embryo xenograft model. A Timeline of the in vivo experiments. The microscopy image shows 3 embryos xenografted with KB cells (red fluorescence). B Toxicity of NPs in xenograft zebrafish embryos injected with DTX and DTX-loaded NPs $([\mathrm{DTX}]=2.5 \mathrm{ng} / \mathrm{animal})$ after 6 days from the treatment. C Tumor volume reduction after
6 days from the treatment with DTX-loaded NPs $([D T X]=2.5 \mathrm{ng} /$ animal). Total tumor fluorescence quantified from images. ${ }^{\S} p<0.05$; ${ }^{\S} p<0.01 ;{ }^{\S \S} p<0.001$ vs. ctrl; ${ }^{*} p<0.001$ vs. free DTX. D Representative images of $\mathrm{KB}$ cells xenotransplanted in the embryo yolks. Scale bars: $500 \mu \mathrm{m}$ 
Fig. 6 Vasculature analysis of flila:EGFP embryos after two days of treatment with nanoparticles (NPs) ([DTX] $=2.5 \mathrm{ng}$ / animal). Fluorescence microscopy images of untreated embryos without (A) or with $\mathrm{KB}$ xenografted cells (B); embryos with KB xenografted cells and treated with free DTX (C) or DTX-DBL ${ }_{\mathrm{Fol} / \mathrm{FLTT} 1}$ (D). $\mathrm{B} 1$ is a magnification showing the presence of vascular branches (white circles) sprouting toward tumor masses in untreated embryos. In the magnification, D1 vascular branches are not visible due to the anti-angiogenic effect exerted by DTX-DBL $\mathrm{Fol}_{/ \mathrm{aFLT} 1}$. Scale bar: $250 \mu \mathrm{m}$. Red: tumor cells stained with DiI; green: zebrafish embryo vasculature
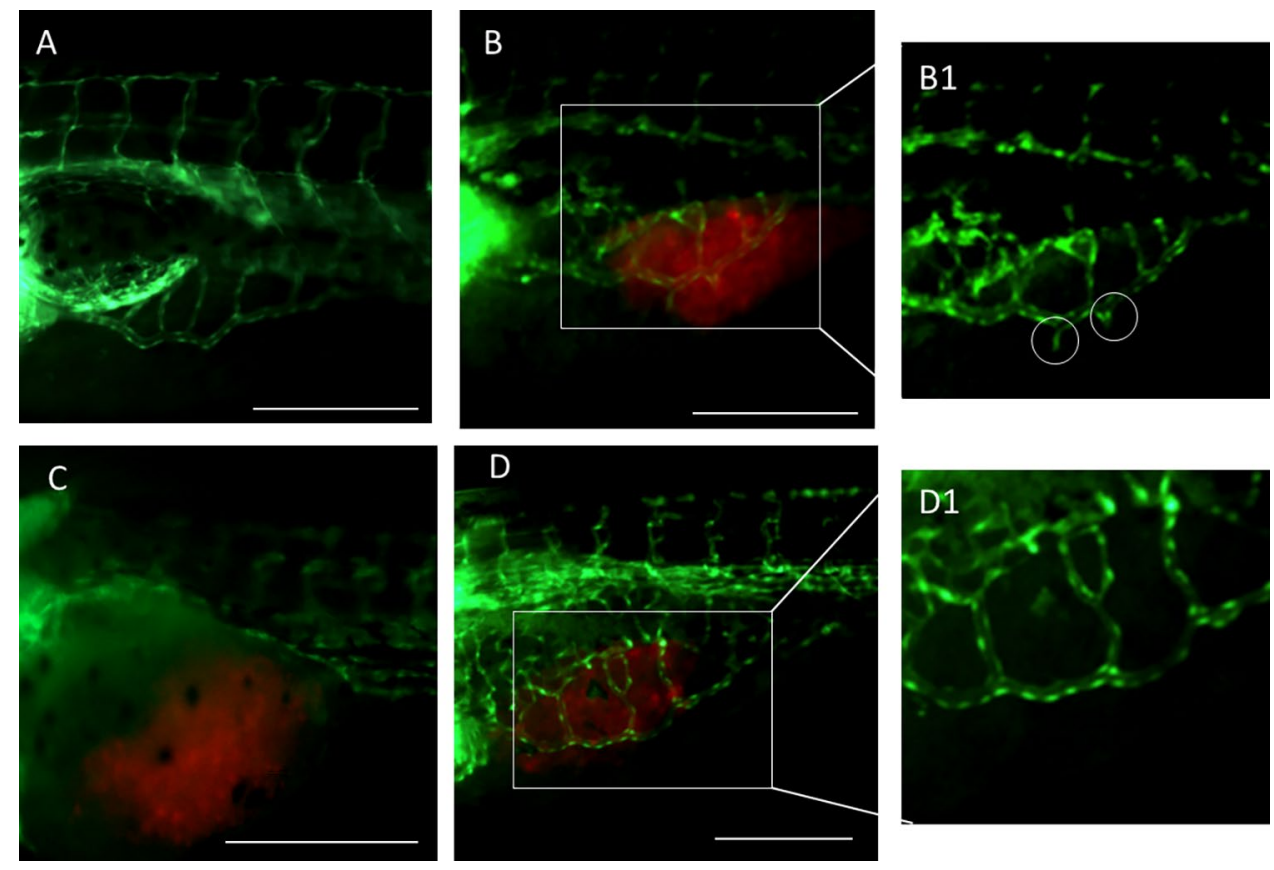

KB cells, and the following day re-injected with DTX, DTXloaded NPs, and unloaded DBL as control. At the time of NP inoculation, KB cells are confined in the yolk of the embryos forming a single mass with spherical shape and a mean diameter of about $600-800 \mu \mathrm{m}$, a size close to that of spheroids tested in vitro (Fig. 5A).

Animal survival analysis revealed that, in the case of embryos xenografted with $\mathrm{KB}$ cells, the percentages of alive animals decreased to $50 \%$ for the control group and all the variants of DTX-loaded NPs (Fig. 5C) as compared with $70 \%$ for the same groups in non-xenografted animals (Fig. S6). Remarkably, DTX treatment reduced the percentage of alive embryos from 70 to $40 \%$ in the nonxenograft embryos (Fig. S6), thus highlighting the role of NPs in protecting the embryo from the high systemic toxicity of DTX.

The efficacy of DTX-loaded NPs in reducing effectively tumor masses was assessed on selected animals bearing a single mass in the yolk 6 days post-treatment. As clearly visible in Fig. 5C, a high reduction of $\mathrm{KB}$-associated fluorescence in all the treated groups compared to control was observed. Notably, the greatest extent of tumor reduction was obtained with DTX-DBL $L_{\text {Fol/aFLT1 }}$, which means that an improvement of DTX efficacy occurs due to both the targeting and the anti-angiogenic motifs. Noteworthy, the presence of Fol on NPs surface did not result in any tumor size reduction improvement compared to untargeted NPs. In fact, three different tumor conditions (indicated as tumor phenotypes) occurred after 6 days of treatment as exemplified with representative images in Fig. S7A: single masses located in the yolk (a), multiple masses located in the yolk (b), tumor masses in the yolk plus distal masses (metastasislike masses) outside yolk region (c). Cell migration from the yolk region is considered indicative of cell invasiveness [45]. The percentages of tumor phenotypes are reported in Fig. S7B. Overall, the extent of cell invasiveness was relatively low $(\sim 20 \%)$, and only $\mathrm{DTX}_{-\mathrm{DBL}} \mathrm{Fol}_{\mathrm{F}}$ significantly reduced $\mathrm{KB}$ cell spread. Moreover, while the number of animals with single or multiple masses in the yolk was comparable in the control group, the treatment with free DTX and DTX-DBL ${ }_{\mathrm{Fol} / \mathrm{aFLT} 1}$ completely abolished the formation of multiple tumor masses, with about $70 \%$ of alive embryos having a single tumor mass. Unlike in vitro observations, tumor regression observed in zebrafish highlighted the superior activity of DTX-DBLFol/aFLT1 compared to free DTX accompanied by a concomitant decrease of DTX systemic toxicity.

To understand if this effect was related to the antiangiogenic activity of DTX-DBL $\mathrm{Fol}_{\mathrm{FFLT1}}$, we employed a fila:EGFP transgenic embryo model. We analyzed eventual macroscopic alterations of blood vessel features $48 \mathrm{~h}$ after NPs injection and compared the results to those collected from untreated or DTX-treated embryos. Figure 6A, B are representative images of an embryo (untreated) xenografted or not with $\mathrm{KB}$ cells, respectively. In both embryos, the intact sub-intestinal vessels (SIVs), with a shape like a basket projected inside the yolk region, are completely formed at this development stage. As clearly visible in Fig. 6, panel B1, and according to some recent pieces of evidence [46], the injection of tumor cells induces pro-angiogenic effects by promoting the formation of additional branches (white circles), which essentially sprout toward the tumor mass. 
Interestingly, the treatment of the xenografted embryos with DTX-DBL ${ }_{\mathrm{Fol} / \mathrm{FLLT} 1}$ prevented the formation of these branches (Fig. 6D, D1), thus suggesting an active role of aFLT1. After DTX treatment, the classic basket structure was not formed (Fig. 6C). The vessels were utterly disorganized within the swollen yolk sack, in line with its superior systemic toxicity.

Taken together, our results demonstrate that tumor regression due to DTX-DBL $\mathrm{Fol}_{\text {aFLT1 }}$ is due to DTX cytotoxicity combined with a significant anti-angiogenic capacity of NPs, which normalize vessels rather than disrupt entirely endothelial cells. Notably, while we were unable to measure any active role of the folate moiety in the in vitro model, DTX-DBL $_{\mathrm{Fol}}$ NPs attenuated the overall toxicity of DTX, demonstrating both an increased anticancer effect and a decreased spread of metastasis in the xenografted zebrafish. The latter observation stresses the importance of the in vivo studies to test NPs efficacy, even using experimental models alternative to rodents as zebrafish, and highlights that threedimensional in vitro models as spheroids are by themselves only poorly predictive of in vivo behavior. In perspective, our results can be considered significant for ovarian cancer, which is eligible for a local treatment aimed to target avascular spheroids dissemination in the peritoneum and to block angiogenesis involved in distal metastasization.

\section{Conclusion}

We have herein reported the development of PEGylated NPs surface-modified with folate/aFLT1 motifs as a strategy to potentiate the activity profile of DTX and to limit its systemic toxicity. The presence of folate on the NP surface did not alter aFLT1 anti-angiogenic activity but affected their penetration in KB spheroids. No significant impact of NP composition on cytotoxicity in the spheroids was found. Remarkably, DTX activity was enhanced in a xenografted zebrafish embryo model when delivered through NPs bearing folate/aFLT1 motifs, whereas DTX toxicity was decreased. To our knowledge, this is the first demonstration that such double decoration of biodegradable PEGylated NPs is feasible and beneficial to increase the efficacy of the bare PEGylated counterpart. Our findings can pave the way to extend this NP concept to other antiangiogenic peptides and chemotherapeutics, widening the arsenal of nanoplatforms to fight solid tumors.

Supplementary information The online version contains supplementary material available at https://doi.org/10.1007/s13346-021-01090-6.

Author contribution F. M. performed the biological studies on cells and contributed to manuscript draft; C.C. performed the studies on nanoparticles and contributed to manuscript draft; D.E. manufactured and characterized the samples; G.D.P synthesized the polymers; C.A. synthesized the peptides; F.U. supervised the characterization studies; N.T. performed the biological studies on zebrafish; A.R. supervised peptide synthetic procedures; P.L. supervised polymer synthetic procedures and drafted the manuscript; E.R. supervised the biological study; F.Q. coordinated the research, analyzed the results, and wrote the manuscript.

Funding This work was supported by the Italian Association for Cancer Research (IG2014 n.15764), the Regione Campania-POR Campania FESR 2014/2020 “Combattere la resistenza tumorale: piattaforma integrata multidisciplinare per un approccio tecnologico innovativo alle oncoterapie-Campania Oncoterapie" (Project N. B61G18000470007) and the Department of Biology, University of Padova (PRIDseed 2018 Grant to FM).

Data availability The raw data are available from the authors.

\section{Declarations}

Ethics approval and consent to participate Not applicable.

Consent for publication All authors have seen and approved the text presented data in this work.

Competing interests The authors declare no competing interests.

Open Access This article is licensed under a Creative Commons Attribution 4.0 International License, which permits use, sharing, adaptation, distribution and reproduction in any medium or format, as long as you give appropriate credit to the original author(s) and the source, provide a link to the Creative Commons licence, and indicate if changes were made. The images or other third party material in this article are included in the article's Creative Commons licence, unless indicated otherwise in a credit line to the material. If material is not included in the article's Creative Commons licence and your intended use is not permitted by statutory regulation or exceeds the permitted use, you will need to obtain permission directly from the copyright holder. To view a copy of this licence, visit http://creativecommons.org/licenses/by/4.0/.

\section{References}

1. Kydd J, Jadia R, Velpurisiva P, Gad A, Paliwal S, Rai P. Targeting strategies for the combination treatment of cancer using drug delivery systems. Pharmaceutics. 2017;9(4):1-26.

2. Raju GSR, Benton L, Pavitra E, Yu JS. Multifunctional nanoparticles: recent progress in cancer therapeutics. Chem Commun. 2015;51(68):13248-59.

3. Karlsson J, Vaughan HJ, Green JJ. Biodegradable polymeric nanoparticles for therapeutic cancer treatments. Annu Rev Chem Biomol Eng. 2018;9:105-27.

4. Kemp JA, Shim MS, Heo CY, Kwon YJ. "Combo" nanomedicine: co-delivery of multi-modal therapeutics for efficient, targeted, and safe cancer therapy. Adv Drug Deliv Rev. 2016;98:3-18.

5. Hillmyer MA, Tolman WB. Aliphatic polyester block polymers: renewable, degradable, and sustainable. Acc Chem Res. 2014;47(8):2390-6.

6. Tian H, Tang Z, Zhuang X, Chen X, Jing X. Biodegradable synthetic polymers: preparation, functionalization and biomedical application. Prog Polym Sci. 2012;37(2):237-80.

7. d'Angelo I, Conte C, Miro A, Quaglia F, Ungaro F. Core-shell nanocarriers for cancer therapy. Part I: biologically oriented design rules. Expert Opin Drug Deliv. 2014;11(2):283-97. 
8. Owens DE, Peppas NA. Opsonization, biodistribution, and pharmacokinetics of polymeric nanoparticles. Int J Pharm. 2006;307(1):93-102.

9. Suk JS, Xu Q, Kim N, Hanes J, Ensign LM. PEGylation as a strategy for improving nanoparticle-based drug and gene delivery. Adv Drug Deliv Rev. 2016;99(Pt A):28-51.

10. Alexis F, Pridgen E, Molnar LK, Farokhzad OC. Factors affecting the clearance and biodistribution of polymeric nanoparticles. Mol Pharm. 2008;5(4):505-15.

11. Conte C, Dal Poggetto G, Swartzwelter BJ, Esposito D, Ungaro F, Laurienzo P, Boraschi D, Quaglia F. Surface exposure of PEG and amines on biodegradable nanoparticles as a strategy to tune their interaction with protein-rich biological media. Nanomaterials (Basel). 2019;9(10):1354.

12. Behzadi S, Serpooshan V, Tao W, Hamaly MA, Alkawareek MY, Dreaden EC, Brown D, Alkilany AM, Farokhzad OC, Mahmoudi M. Cellular uptake of nanoparticles: journey inside the cell. Chem Soc Rev. 2017;46(14):4218-44.

13. Danhier F, Feron O, Preat V. To exploit the tumor microenvironment: passive and active tumor targeting of nanocarriers for anticancer drug delivery. J Control Release. 2010;148(2):135-46.

14. Farran B, Montenegro RC, Kasa P, Pavitra E, Huh YS, Han Y-K, Kamal MA, Nagaraju GP, Rama Raju GS. Folate-conjugated nanovehicles: strategies for cancer therapy. Mater Sci Eng C. 2020;107:110341.

15. Valencia PM, Hanewich-Hollatz MH, Gao W, Karim F, Langer R, Karnik R, Farokhzad OC. Effects of ligands with different water solubilities on self-assembly and properties of targeted nanoparticles. Biomaterials. 2011;32(26):6226-33.

16. Kularatne SA, Low PS. Targeting of nanoparticles: folate receptor. Methods Mol Biol. 2010;624:249-65.

17. Venuta A, Moret F, Dal Poggetto G, Esposito D, Fraix A, Avitabile C, Ungaro F, Malinconico M, Sortino S, Romanelli A, Laurienzo P, Reddi E, Quaglia F. Shedding light on surface exposition of poly(ethylene glycol) and folate targeting units on nanoparticles of poly(epsilon-caprolactone) diblock copolymers: beyond a paradigm. Eur J Pharm Sci. 2018;111:177-85.

18. Conte C, Fotticchia I, Tirino P, Moret F, Pagano B, Gref R, Ungaro F, Reddi E, Giancola C, Quaglia F. Cyclodextrin-assisted assembly of PEGylated polyester nanoparticles decorated with folate. Colloids Surf B Biointerfaces. 2016;141:148-57.

19. Zuazo-Gaztelu I, Casanovas O. Unraveling the role of angiogenesis in cancer ecosystems. Front Oncol. 2018;8:248.

20. Atukorale PU, Covarrubias G, Bauer L, Karathanasis E. Vascular targeting of nanoparticles for molecular imaging of diseased endothelium. Adv Drug Deliv Rev. 2017;113:141-56.

21. Sakurai $\mathrm{Y}$, Akita H, Harashima H. Targeting tumor endothelial cells with nanoparticles. Int J Mol Sci. 2019;20(23):5819.

22. Valkenburg KC, de Groot AE, Pienta KJ. Targeting the tumour stroma to improve cancer therapy. Nat Rev Clin Oncol. 2018;15(6):366-81.

23. Kamba T, McDonald DM. Mechanisms of adverse effects of antiVEGF therapy for cancer. Br J Cancer. 2007;96(12):1788-95.

24. Vasudev NS, Reynolds AR. Anti-angiogenic therapy for cancer: current progress, unresolved questions and future directions. Angiogenesis. 2014;17(3):471-94.

25. Benny O, Fainaru O, Adini A, Cassiola F, Bazinet L, Adini I, Pravda E, Nahmias Y, Koirala S, Corfas G, D'Amato RJ, Folkman J. An orally delivered small-molecule formulation with antiangiogenic and anticancer activity. Nat Biotechnol. 2008;26(7):799-807.

26. Ebos JML, Lee CR, Kerbel RS. Tumor and host-mediated pathways of resistance and disease progression in response to antiangiogenic therapy. Clin Cancer Res. 2009;15(16):5020-5.

27. Kargozar S, Baino F, Hamzehlou S, Hamblin MR, Mozafari M. Nanotechnology for angiogenesis: opportunities and challenges. Chem Soc Rev. 2020;49(14):5008-57.
28. Bae DG, Kim TD, Li G, Yoon WH, Chae CB. Anti-flt1 peptide, a vascular endothelial growth factor receptor 1-specific hexapeptide, inhibits tumor growth and metastasis. Clin Cancer Res. 2005;11(7):2651-61.

29. Fischer C, Mazzone M, Jonckx B, Carmeliet P. FLT1 and its ligands VEGFB and PlGF: drug targets for anti-angiogenic therapy? Nat Rev Cancer. 2008;8(12):942-56.

30. Conte C, Moret F, Esposito D, Dal Poggetto G, Avitabile C, Ungaro F, Romanelli A, Laurienzo P, Reddi E, Quaglia F. Biodegradable nanoparticles exposing a short anti-FLT1 peptide as antiangiogenic platform to complement docetaxel anticancer activity. Mater Sci Eng C. 2019;102:876-86.

31. Palma G, Conte C, Barbieri A, Bimonte S, Luciano A, Rea D, Ungaro F, Tirino P, Quaglia F, Arra C. Antitumor activity of PEGylated biodegradable nanoparticles for sustained release of docetaxel in triple-negative breast cancer. Int J Pharm. 2014;473(1-2):55-63.

32. Endres TK, Beck-Broichsitter M, Samsonova O, Renette T, Kissel TH. Self-assembled biodegradable amphiphilic PEG-PCL-lPEI triblock copolymers at the borderline between micelles and nanoparticles designed for drug and gene delivery. Biomaterials. 2011;32(30):7721-31.

33. Gaio E, Scheglmann D, Reddi E, Moret F. Uptake and phototoxicity of Foscan(R), Foslip(R) and Fospeg(R) in multicellular tumor spheroids. J Photochem Photobiol B Biol. 2016;161:244-52.

34. Gaio E, Guerrini A, Ballestri M, Varchi G, Ferroni C, Martella E, Columbaro M, Moret F, Reddi E. Keratin nanoparticles co-delivering docetaxel and chlorin e6 promote synergic interaction between chemo- and photo-dynamic therapies. J Photochem Photobiol B Biol. 2019;199:111598.

35. Westerfield M. The zebrafish book. A guide for the laboratory use of zebrafish (Danio rerio). 4th ed.; Univ. of Oregon Press, Eugene.: 2000.

36. Kimmel CB, Ballard WW, Kimmel SR, Ullmann B, Schilling TF. Stages of embryonic development of the zebrafish. Dev Dyn. 1995;203(3):253-310.

37. Millard M, Yakavets I, Zorin V, Kulmukhamedova A, Marchal S, Bezdetnaya L. Drug delivery to solid tumors: the predictive value of the multicellular tumor spheroid model for nanomedicine screening. Int J Nanomed. 2017;12:7993-8007.

38. Barros TP, Alderton WK, Reynolds HM, Roach AG, Berghmans S. Zebrafish: an emerging technology for in vivo pharmacological assessment to identify potential safety liabilities in early drug discovery. Br J Pharmacol. 2008;154(7):1400-13.

39. Mimeault M, Batra SK. Emergence of zebrafish models in oncology for validating novel anticancer drug targets and nanomaterials. Drug Discov Today. 2013;18(3-4):128-40.

40. Zhao C, Yang H, Shi H, Wang X, Chen X, Yuan Y, Lin S, Wei $Y$. Distinct contributions of angiogenesis and vascular co-option during the initiation of primary microtumors and micrometastases. Carcinogenesis. 2011;32(8):1143-50.

41. Stoletov K, Kato H, Zardouzian E, Kelber J, Yang J, Shattil S, Klemke R. Visualizing extravasation dynamics of metastatic tumor cells. J Cell Sci. 2010;123(Pt 13):2332-41.

42. Sieber S, Grossen P, Bussmann J, Campbell F, Kros A, Witzigmann D, Huwyler J. Zebrafish as a preclinical in vivo screening model for nanomedicines. Adv Drug Deliv Rev. 2019;151-152:152-68.

43. Fazio M, Ablain J, Chuan Y, Langenau DM, Zon LI. Zebrafish patient avatars in cancer biology and precision cancer therapy. Nat Rev Cancer. 2020;20(5):263-73.

44. Sousa F, Costa-Pereira AI, Cruz A, Ferreira FJ, Gouveia M, Bessa J, Sarmento B, Travasso RDM, Mendes Pinto I. Intratumoral VEGF nanotrapper reduces gliobastoma vascularization and tumor cell mass. J Control Release. 2021;339:381-90. 
45. Gaudenzi G, Albertelli M, Dicitore A, Wurth R, Gatto F, Barbieri F, Cotelli F, Florio T, Ferone D, Persani L, Vitale G. Patient-derived xenograft in zebrafish embryos: a new platform for translational research in neuroendocrine tumors. Endocrine. 2017;57(2):214-9.

46. Wu JQ, Zhai J, Li CY, Tan AM, Wei P, Shen LZ, He MF. Patientderived xenograft in zebrafish embryos: a new platform for translational research in gastric cancer. J Exp Clin Cancer Res. 2017;36(1):160.
Publisher's Note Springer Nature remains neutral with regard to jurisdictional claims in published maps and institutional affiliations. 